\title{
The Great Recession and Immune Function
}

\author{
ELIZABETH MCCLURE, LYDIA FEINSTEIN, SARA FERRANDO- \\ MARTÍNEZ, MANUEL LEAL, SANDRO GALEA, AND \\ ALLISON E. AIELLO
}

The Great Recession precipitated unprecedented home foreclosures increases, but documentation of related neighborhood changes and population health is scant. Using the Detroit Neighborhood Health Study ( $N=$ 277), we examined associations between neighborhood-level recession indicators and thymic function, a life course immunological health indicator. In covariate-adjusted multilevel models, each 10 percentage point increase in abandoned home prevalence and 1 percentage point increase in 2009 home foreclosures was associated with 1.7-year and 3.3-year increases in thymic aging, respectively. Associations attenuated after adjustment for neighborhood-level social cohesion, suggesting community ties may buffer recession-related immune aging. Effects of neighborhood stressors were strongest in middle-income households, supporting theory of excess vulnerability in this group. Future research should assess whether ongoing foreclosure and blight reduction efforts improve health for residents of recession impacted neighborhoods.

Keywords: neighborhood, social determinants of health, Detroit, immunity, immunosenescence, thymic function

In December 2007, the United States began to experience one of the most stressful economic downturns in its history. This period-now referred to as the Great Recession-resulted in a disconcerting combination of job losses, fewer new jobs, and massive declines in housing and equity values that had not been seen for almost a century (Mishel et al. 2012; Gould Ellen and Dastrup 2012; Flanagan and Wilson 2013). Given the enormity of the changes in economic conditions during the Great Recession, it is not surprising that emerging evidence has linked economic stressors over this period to a range of negative health outcomes, including decreases in self-rated health, poor mental health, and substance abuse (Burgard, Seefeldt, and Zelner 2012; Riumallo-Herl et al. 2014; Mulia et al. 2014; Bacigalupe and Escolar-Pujolar 2014; McLaughlin et al. 2012; Tsai 2015; Cagney et al. 2014; Pollack et al. 2011). Other sources of stress

Elizabeth McClure is a predoctoral trainee at the Carolina Population Center and Department of Epidemiology, University of North Carolina at Chapel Hill. Lydia Feinstein is an epidemiologist at Social \& Scientific Systems, Inc. Sara Ferrando-Martínez is a scientist at Medlmmune. Manuel Leal is faculty at the Laboratory of Immunovirology, Clinic Unit of Infectious Diseases, Microbiology and Preventive Medicine, Institute of Biomedicine of Seville, IBiS, Virgen del Rocio University Hospital, Seville, Spain. Sandro Galea is dean of the Boston University School of Public Health. Allison E. Aiello is faculty at the Carolina Population Center and Department of Epidemiology, University of North Carolina at Chapel Hill.

(C) 2018 Russell Sage Foundation. McClure, Elizabeth, Lydia Feinstein, Sara Ferrando-Martínez, Manuel Leal, Sandro Galea, and Allison E. Aiello. 2018. "The Great Recession and Immune Function." RSF: The Russell Sage Foundation Journal of the Social Sciences 4(4): 62-81. DOI: 10.7758/RSF.2018.4.4.04. Direct correspondence to: Elizabeth McClure at emcclure@unc.edu; and Allison E. Aiello at aaiello@unc.edu, 2101C Mcgavran-Greenberg Hall, CB \#7435, Chapel Hill, NC 27599.

Open Access Policy: RSF: The Russell Sage Foundation Journal of the Social Sciences is an open access journal. This article is published under a Creative Commons Attribution-NonCommercial-NoDerivs 3.0 Unported License. 
were likely experienced at the community level. One of the most profound impacts was a steep rise in home foreclosures that fueled a proliferation of abandoned homes across the country. Despite the magnitude of home vacancies that followed the economic downturn, little is known about how this fundamental change in the neighborhood physical environment has impacted the health of residents in highly affected communities.

The economic impact of the Great Recession was especially profound in the state of Michigan: in the wake of the crisis, the unemployment rate doubled from an average of 6 percent before the crisis (2000-2007) to approximately 14 percent by 2009 (Bureau of Labor Statistics 2015). Even among residents fortunate enough to retain their jobs, many faced steep declines in asset values, including homes and equities. Indeed, median home values fell nearly 30 percent from their pre-crisis peak, and between 2005 and 2010 more than four hundred thousand residential units in both urban and rural areas faced a foreclosure auction filing (Michigan Foreclosure Task Force 2016). Although economic conditions worsened across the state, Detroit's economy was suffering before the Great Recession. Relative to its population peak in 1950, Detroit lost half of its residents by the beginning of the recession (Sugrue 2014). Detroit's history of racial segregation and industrial losses before the Great Recession uniquely left many neighborhoods in the city of Detroit particularly vulnerable to home foreclosures and other economic stressors (Lichter, Parisi, and Taquino 2015).

The quality of the neighborhood physical environment is increasingly being implicated as a key determinant of population health (Kawachi and Berkman 2003). Indeed, poor neighborhood physical environments contribute to the degradation of communities in the form of increased exposure to violence and reductions in social cohesion, both of which have been linked to negative health outcomes (Smith et al. 1998; Diez Roux et al. 2001; Giurgescu et al. 2015; Drukker and van Os 2003; Kruger, Reischl, and Gee 2007; Curry, Latkin, and DaveyRothwell 2008; Tonorezos et al. 2008; WilsonGenderson and Pruchno 2013; Blair et al. 2014).

To date, the biological mechanisms through which the neighborhood environment influences health are poorly understood (Steptoe and Marmot 2002). Prior studies linking individual-level socioeconomic stressors to decreased immune response (Dhabhar 2014; Dowd and Aiello 2009) suggest that the immune system may be an important biological pathway for understanding how neighborhoodlevel economic stressors may affect health (Steptoe 2012). Nonetheless, few studies have incorporated salient immunological biomarkers into population-based research on the social determinants of health. This dearth of research has made it difficult to examine the role of the immune systems as a central biological barometer of exposure to stressors. Studies examining neighborhood-level social determinants and immune function are currently limited to downstream immune biomarkers, such as indicators of elevated levels of inflammation and antibodies to cytomegalovirus infection (Keita et al. 2014; Lantos et al. 2015; Ford and Browning 2015).

Evidence is accumulating that the process of thymic involution, or the shrinking of the thymus over the life course and the associated reduction in naïve T-cells, may be an important indicator of immunological health at the population level (Ferrando-Martínez et al. 2009; Feinstein et al. 2016). As the main organ for de novo naïve T-cell production, the thymus plays an essential and global role in the quality of immune response (Steptoe 2012), and animal studies have shown that exposure to stressors reduces thymic output of naïve T-cells (Gruver and Sempowski 2008). Although the thymus is thought to recover following exposure to stressful events, the immune system is left vulnerable during these periods of reduced thymic function, increasing susceptibility to foreign pathogens (Gruver and Sempowski 2008). Whether recurring or prolonged periods of stress-induced atrophy over the life course result in a cumulative health impact in the long term remains unknown. Thymic function has only recently been characterized in a community-based cohort (Feinstein et al. 2016), and no study we are aware of has examined the relation between neighborhood characteristics and the population distribution of thymic function. Further, the literature has yet to identify 
Figure 1. Conceptual Model, Neighborhood Economic Stressors on Immune Function

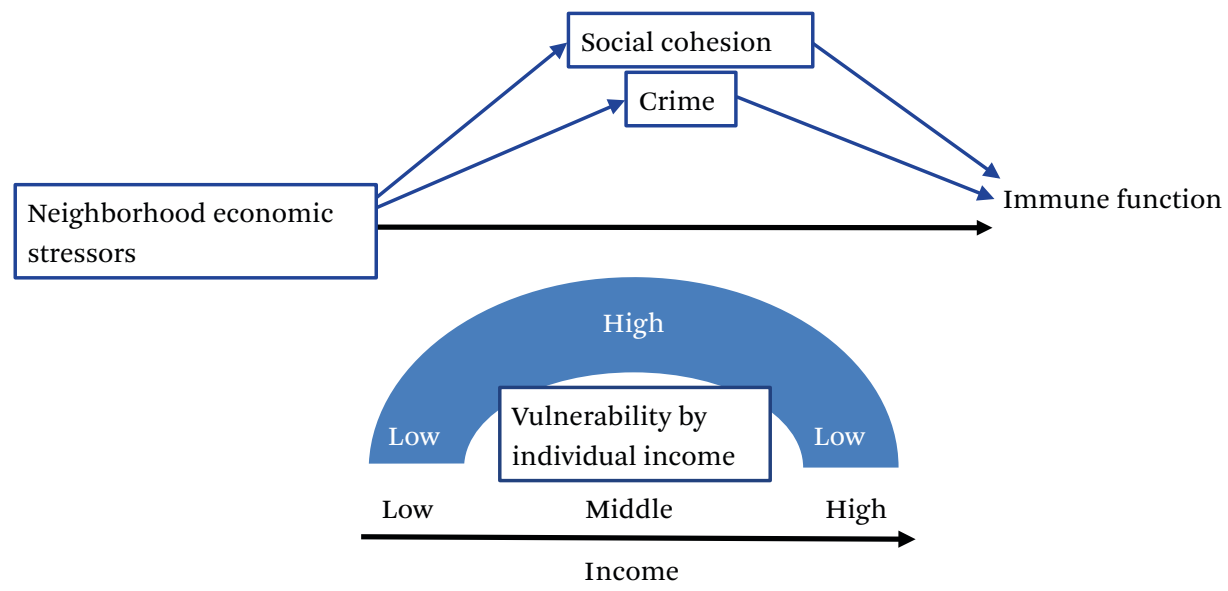

Source: Authors' calculations.

particular community-level characteristics through which the neighborhood physical environment may influence stress-related immunological alterations, or whether individual characteristics may buffer these area-level influences with regard to immune function.

The need and the opportunity to understand the mechanisms through which arealevel economic stressors affect population health are pressing. We conducted the first analysis of this type using data from the Detroit Neighborhood Health Study (DNHS), a population-based cohort study of primarily African American adults that began data collection in 2008 , near the very beginning of the economic downturn. The purpose of this study was to begin to develop hypotheses for the mechanisms through which the social environment affects health through the immune system. Figure 1 presents a conceptual model informed by the population health evidence and theory described, which suggests that immune function may be sensitive to acute and chronic neighborhood-level economic stress. Further, it shows two pathways through which these area-level stressors are embodied in diminished immune function-increased exposure to crime and decreased social cohesion. Finally, the literature indicates that individual socioeconomic status may buffer the negative impacts of area-level stressors on immune function, but none of the pathways shown has been assessed analytically. We hypothesized that liv- ing in a neighborhood with a higher prevalence of abandoned homes and home foreclosures would be associated with lower thymic function, in part due to increased exposure to neighborhood crime and loss of neighborhood social cohesion. Further, because evidence suggests that the Great Recession was particularly harmful to those with middle-class incomes (Ackerman, Fries, and Windle 2012), we additionally hypothesized that low- and high-income individuals would be less susceptible to effects of increases in foreclosures or abandoned homes, resulting in smaller decreases in thymic function, whereas middle-income individuals would experience the largest decrease in thymic function.

Motivated by our conceptual model, we first assessed the association between neighborhoodlevel environmental stressors associated with the Great Recession-including the prevalence of abandoned homes and home foreclosuresand thymic function; second, we characterized the roles of neighborhood crime and social cohesion as potential mediators of these associations; and third, we determined whether the effects of increases in foreclosures and abandoned homes on thymic function were modified by individual-level socioeconomic status.

\section{METHODS}

The DNHS was conducted in five waves from 2008 to 2013. In the first study wave (2008-2009), 1,547 participants were recruited using a two- 
Figure 2. Timeline for Relevant Measurements, Detroit Neighborhood Health Study

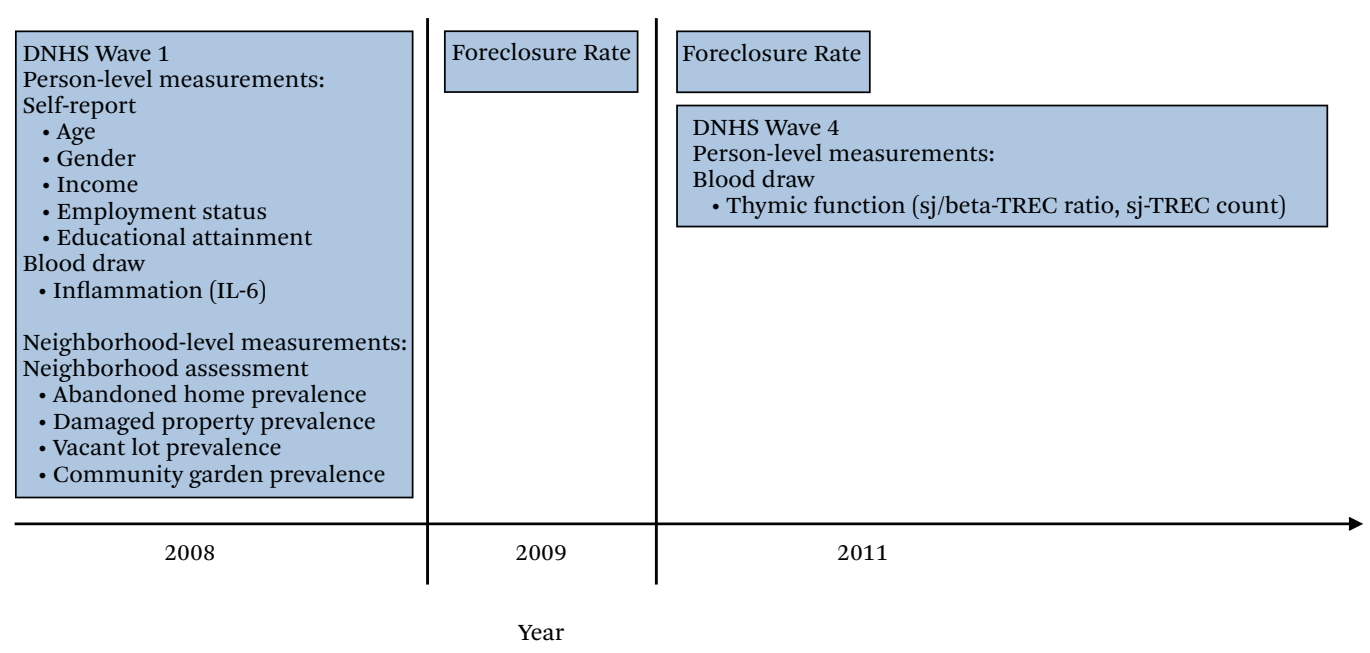

Source: Authors' calculations from the Detroit Neighborhood Health Study, 2008-2013.

stage area probability sample of households in the city limits (Goldmann et al. 2011). A telephone survey captured participants' demographic and socioeconomic information, health characteristics, social support, and exposure to trauma. In addition to the telephone survey, participants also had the option to provide a venous blood sample at their homes. Participants for whom thymic function was assessed and for whom complete residential location and covariate information was available were eligible for inclusion in the present analysis, resulting in a final sample size of 277. Figure 2 summarizes the DNHS study design and timing of each measurement described.

\section{Measures}

Of Detroit's fifty-four historically defined neighborhoods, fifty-two included DNHS study participants with available data for analysis (Hill and Gallagher 2002). We used these historically defined neighborhoods as the boundaries for neighborhood analyses. To capture characteristics of the neighborhood physical and social environment, a baseline neighborhood assessment was conducted by trained observers in 2008, many of whom were Detroit residents (Momper et al. 2012). Observers were assigned road sections for direct observation and assessed the presence of environmental factors, like abandoned homes (yes or no), on each street segment. Areas not directly assessed were assigned a value using spatial kriging of the directly assessed areas, as previously done in spatial analyses of urban environment (Auchincloss et al. 2007). The scores for each indicator were aggregated to the neighborhood level, with the prevalence measure representing the proportion of block segments in the neighborhood for which the answer to the abandoned homes question was yes (Momper et al. 2012). Other indicators of physical environmental qualityprevalence of damaged properties, vacant lots, and community gardens - were also measured as part of the neighborhood assessment. The score for each indicator was assessed independently and as a combined physical environmental quality score, all measured continuously at the neighborhood level for the present analysis. Community garden prevalence was reverse coded for the composite score.

The number of foreclosed properties in 2009 and 2011 by census tract were obtained from RealtyTrac, an authoritative source for historic United States real estate statistics and foreclosure trends (RealtyTrac 2011). Proportions were constructed as number of foreclosed properties divided by the number of total mortgages in each year within neighborhoods. The proportion for each year and the change in proportions between 2009 and 2011 was assessed in relation to thymic function. 
Outcome: Thymic Function

Participant DNA was extracted from venous whole blood samples, frozen and stored at $-70^{\circ} \mathrm{C}$, and shipped on dry ice to the Laboratory of Immunovirology at the University of Seville for thymic function quantification. T-cell receptor (TCR) excision circles (TRECs) are nonreplicated extrachromosomal DNA byproducts of alpha (signal joint) and beta chain TCR rearrangements that occur during the production of new T-cells (Lynch and Sempowski 2013). In this analysis, thymic function was measured by the ratio of signal joint to beta TRECs (sj/beta-TREC ratio). The sj/beta-TREC ratio was assessed in genomic DNA and analyses included a two-round quantitative PCR (qPCR) protocol, which is described in various studies (Ferrando-Martínez et al. 2010, 2013; Feinstein et al. 2016). The thymus is located near the heart, so direct measurement of its function is clinically contraindicated. The quantification of sjTREC is a more widely used indirect measurement of thymic function than the sj/beta-TREC ratio (Douek et al. 1998; Dion et al. 2007). However, sjTREC may be diluted by proliferation of naïve T-cells in peripheral blood, which can result in a reduction in number of sjTREC without a reduction in thymic function (Dion et al. 2004). The sj/beta-TREC ratio measure, used in this analysis, was developed to address the issue because it enables more direct estimation of intrathymic proliferation of T-cells, with regard to peripheral activity (Dion et al. 2004; Ferrando-Martínez et al. 2010). Thymic function was assessed in blood collected during the fourth study wave (2011) and is treated here as a continuous outcome, natural log-transformed to approximate a normal distribution.

\section{Covariates}

Neighborhood levels of social cohesion and crime were examined as potential mediators of the association between the prevalence of abandoned homes and thymic function. Social cohesion was assessed in the first study wave by asking respondents whether they agreed on a 5 -point Likert scale ( 1 = strongly disagree, 5 = strongly agree) with a series of statements related to whether their neighborhood is unified, residents are willing to help each other, neighbors get along, neighbors share common values, and neighbors can be trusted (McLaughlin et al. 2012). Responses were summed for each respondent, averaged at the neighborhood level, and treated as continuous scores out of 100 , such that lower scores represent a lower degree of social cohesion.

Neighborhood crime levels were assessed using geocoded crime incidents occurring from January 1, 2009, through December 31, 2009, extracted from the Detroit Police Department's CrisNet/NetRMS records management system (Detroit Police Department 2009). Incidents with valid geocodes were summed at the neighborhood level and modeled in the present analysis as number of incidents per square mile, weighted for neighborhood population density.

Age, gender (male or female), baseline immunological status, and socioeconomic status were identified a priori as potential confounders via a directed acyclic graph (Greenland, Pearl, and Robins 1999) and included as covariates in adjusted models. Because thymic function was available only in wave 4 , we quantified and controlled for a proxy for immunological status which was measured at the time of the baseline survey, serum levels of Interleukin-6 (IL-6), a marker of inflammation (DelaRosa et al. 2006; Hunter and Jones 2015) that has been shown to strongly predict thymic function in the DNHS population (Feinstein et al. 2016). Employment status at the time of the baseline survey was included as a marker of socioeconomic status and categorized into three levels: employed, unemployed, and other (such as retired, homemaker, student, on maternity or paternity leave, sick leave, and on disability). Additional indicators of socioeconomic status collected at baseline included education, dichotomized as high school or less versus beyond high school, and an ordinal indicator of household income (less than $\$ 25,000, \$ 25,000$ to less than $\$ 50,000$, or $\$ 50,000$ or more per year).

\section{Statistical Analyses}

Standard descriptive statistics were used to characterize the study population. Medians and interquartile ranges (IQRs) were calculated for 
continuous variables. Counts and percentages were assessed for categorical variables. We used descriptive spatial analyses to generate maps displaying the unadjusted foreclosure prevalences, prevalence of abandoned homes, social cohesion scores, and population-density weighted crime incidents per square mile by neighborhood.

Two-level random intercept linear regression models, with participants nested within neighborhoods, were used to estimate the association between neighborhood prevalence of abandoned homes and thymic function (Subramanian and O'Malley 2010). Next, analyses were conducted to assess whether changes in proportion of homes foreclosed during the Great Recession influence thymic function. Models were run to examine the association between thymic function and neighborhood foreclosure proportions in 2009, 2011, and the change in proportion between these two periods. To further untangle the specificity of the foreclosure effect, we examined three additional neighborhood physical quality measures in relation to thymic function-prevalence of damaged properties, vacant lots, and community gardens-as well as a composite measure derived as a sum of all four exposures, with the community gardens prevalence reverse coded. Models were first adjusted only for participant age and then additionally sex, baseline immunological status, and employment status. Age was modeled in all analyses using a four-node cubic spline to better fit any curvature in the age-thymic function relationship (Howe et al. 2011).

To assess whether neighborhood levels of social cohesion and crime mediated the associations of both 2009 prevalence of foreclosures and neighborhood prevalence of abandoned homes with thymic function, we first examined the extent to which these potentially mediating variables were independently associated with neighborhood foreclosures and abandoned homes, as well as with thymic function. We then examined whether the overall association of foreclosures and neighborhood prevalence of abandoned homes with thymic function was attenuated by additionally adjusting for social cohesion, then crime.
To assess effect modification by individuallevel socioeconomic status, we then examined the associations between neighborhood abandoned home prevalence as well as neighborhood foreclosure measurement and participant thymic function in analyses stratified by annual household income level (less than $\$ 25,000$, $\$ 25,000$ to less than $\$ 50,000$, or $\$ 50,000$ or more per year). A separate model was run for each stratum, adjusting for age, sex, and baseline immunological status. Statistical significance of modification was tested with an interaction term in the full model between income and each exposure (abandoned home prevalence and neighborhood foreclosures).

Spatial analyses and aggregation were completed in ArcMaps 10.3.1 (Environmental Systems Research Institute, Redlands, CA). All other statistical analyses were conducted in SAS 9.4 (SAS Institute, Inc.).

\section{Sensitivity Analyses}

We conducted a sensitivity analysis using the absolute number of sjTREC per million whole blood, rather than sj/beta-TREC ratio as the outcome. The sjTREC number remains the most commonly applied measure of thymic function in the literature (Douek et al. 1998; Dion et al. 2007). It may have logistical advantages for application in large-scale populationbased studies compared to the $\mathrm{sj} /$ beta-TREC ratio, which requires a more extensive laboratory methodology for analysis (Lynch et al. 2009). We also tested associations using baseline IL-6 as the outcome.

To determine whether our overall models were sensitive to the marker of socioeconomic status included, we examined the association between neighborhood prevalence of abandoned homes and thymic function as measured by the sj/beta-TREC ratio adjusting for education and then household income instead of employment status.

\section{RESULTS}

There were 277 participants included in the present analysis. Table 1 shows the distributions of sociodemographic characteristics of the study population, overall and stratified by neighborhood levels of abandoned homes. 
Table 1. Sample Characteristics by Prevalence of Abandoned Homes, Detroit Neighborhood Health Study

\begin{tabular}{|c|c|c|c|}
\hline Measure & $\begin{array}{l}\text { Full Sample } \\
\qquad(\mathrm{N}=277)\end{array}$ & $\begin{array}{c}\text { Prevalence } \\
\quad<15 \% \\
(\mathrm{~N}=125)\end{array}$ & $\begin{array}{c}\text { Prevalence } \\
>15 \% \\
(\mathrm{~N}=152)\end{array}$ \\
\hline Age, median (IQR) & $56(47-67)$ & $59(53-71)$ & $56(47-66)$ \\
\hline Female, N (\%) & $167(61)$ & $74(69)$ & $93(61)$ \\
\hline Employed, N (\%) & $96(35)$ & $11(32)$ & $85(35)$ \\
\hline Unemployed, N (\%) & $39(14)$ & 1 (3) & $38(16)$ \\
\hline Other employment status, $\mathrm{N}(\%)^{\mathrm{a}}$ & $142(51)$ & $22(65)$ & $120(49)$ \\
\hline Interleukin 6 (IL-6), median (IQR) & $3(2-4)$ & $4(2-5)$ & $3(2-5)$ \\
\hline $\begin{array}{l}\text { Neighborhood prevalence of abandoned homes, } \\
\text { median (IQR) }\end{array}$ & $34(23-45)$ & $14(9-14)$ & $35(28-45)$ \\
\hline $\begin{array}{l}\text { Neighborhood prevalence of damaged } \\
\text { properties, median (IQR) }\end{array}$ & $33(25-42)$ & $14(5-16)$ & $38(29-43)$ \\
\hline $\begin{array}{l}\text { Neighborhood prevalence of vacant lots, } \\
\text { median (IQR) }\end{array}$ & $30(13-52)$ & $6(2-13)$ & $33(15-53)$ \\
\hline $\begin{array}{l}\text { Neighborhood prevalence of community } \\
\text { gardens, median (IQR) }\end{array}$ & $0(0-1)$ & $0(0-0)$ & $0(0-1)$ \\
\hline $\begin{array}{l}\text { Neighborhood foreclosure prevalence } 2009 \\
\text { median (IQR) }\end{array}$ & $3(2-4)$ & $2(1-3)$ & $3(2-5)$ \\
\hline $\begin{array}{l}\text { Neighborhood foreclosure prevalence } 2011 \\
\text { median (IQR) }\end{array}$ & $2(1-2)$ & $2(1-2)$ & $2(1-2)$ \\
\hline $\begin{array}{l}\text { Neighborhood foreclosure rate change 2009- } \\
2011 \text {, median (IQR) }\end{array}$ & $-1(-2-0)$ & $-2(-3-1)$ & $1(-1-2)$ \\
\hline $\begin{array}{l}\text { Neighborhood social cohesion score, median } \\
\text { (IQR) }\end{array}$ & $52(40-60)$ & $60(48-72)$ & $48(36-60)$ \\
\hline Crimes per square mile, median (IQR) & $436(374-516)$ & $436(369-492)$ & $587(410-593)$ \\
\hline sj/beta-TREC ratio, median (IQR) & $5(1-19)$ & $5(1-19)$ & $5(1-18)$ \\
\hline
\end{tabular}

Source: Authors' calculations from the Detroit Neighborhood Health Study, 2008, and Detroit Police Department 2009.

aOther includes retired, homemaker, student, maternity-paternity leave, illness = sick leave, and disability.

Overall, participants were a median of fifty-six years old (IQR: forty-seven to sixty-seven years), had a median IL-6 measure of $3 \mathrm{pg} / \mathrm{mL}$ (IQR: $2-4 \mathrm{pg} / \mathrm{mL}$ ), 61 percent were female, 35 percent were currently employed, 14 percent were unemployed, and 51 percent were retired, students, homemakers, or other (employment status). The median neighborhood prevalence of abandoned homes was 34 percent (IQR: 23 to 45 percent), that of damaged properties was 33 percent (IQR: 25 to 42 percent), vacant lots was 30 percent (IQR: 13 to 52 percent), and community gardens was 0 percent (IQR: 0 to 1 percent). Median neighborhood foreclosure proportion was 3 percent (IQR: 2 to 4 percent) in 2009 and 2 percent (IQR: 1 to 2 percent) in 2011. The median change in foreclosure proportion between 2011 and 2009 was -1 (IQR: -2 to 0 ) percentage points. Participants living in areas with a higher prevalence of abandoned homes (more than 15 percent) were more likely to be unemployed than those living in a neighborhood with a lower prevalence of abandoned homes ( 16 percent versus 3 percent unemployed, respectively). Those living in areas with a higher prevalence of abandoned homes were also slightly younger and more likely to be male. Respondents living in 
Table 2. Sample Characteristics Versus Wave 1 Population, Detroit Neighborhood Health Study

\begin{tabular}{lcc}
\hline Measure & $\begin{array}{c}\text { Sample } \\
(\mathrm{N}=277)\end{array}$ & $\begin{array}{c}\text { DNHS Wave 1 } \\
\text { Population } \\
(\mathrm{N}=1,547)\end{array}$ \\
\hline Age, median (IQR) & $56(47-67)$ & $48(35-56)$ \\
Female, $\mathrm{N}(\%)$ & $167(61)$ & $833(54)$ \\
Employed, $\mathrm{N}(\%)$ & $97(35)$ & $738(52)$ \\
Income, $\mathbf{N}(\%)$ & & \\
$\quad$ Less than $\$ 25,000$ & $141(51)$ & $738(48)$ \\
$\$ 25,000-\$ 49,999$ & $89(32)$ & $452(29)$ \\
$\$ 50,000$ or more & $47(17)$ & $357(23)$ \\
\hline
\end{tabular}

Source: Authors' calculations from the Detroit Neighborhood Health Study, 2008, and Detroit Police Department 2009.

neighborhoods with a lower prevalence of abandoned homes were more likely to live in areas with greater social cohesion (60 percent versus 48 percent) and less crime (436 versus 587 crimes per square mile), damaged properties (14 percent versus 38 percent), vacant lots ( 6 percent versus 33 percent), and foreclosures in 2009 ( 2 versus 3 percent) than respondents living in neighborhoods with more abandoned homes. Measured characteristics in our sample differed slightly from those in the entire study population at wave 1 . Our study sample had an older median age and a larger proportion female, unemployed, and of low income (table 2).

\section{Main Findings}

Thymic function, as measured by the sj/betaTREC ratio, was at a statistically significant lower level among participants living in neighborhoods with more abandoned homes. A 10 percentage point increase in the prevalence of abandoned homes was associated with a -0.03 (95\% CI: -0.05, -0.01) log-unit decrease in $\mathrm{sj} /$ beta-TREC ratio, after controlling for age, sex, baseline IL-6, and employment status. Similar to the association with abandoned homes, neighborhood foreclosure proportions in 2009 and 2011 were associated with thymic function such that a one-unit increase in foreclosure proportion was associated with a -0.06 (95\% CI: $-0.11,-0.01)$ log-unit decline in sj/beta-TREC ratio in 2009 and a -0.04 (95\% CI: $-0.09,0.00$ ), log-unit decline in 2011. The association by change in foreclosure proportion over this period was not significant, $\beta=-0.19$ (95\% CI: $-0.62,0.24)$.

None of the three other neighborhood characteristics assessed were statistically significantly associated with thymic function: prevalence of damaged property, $\beta=-0.04$ (95\% CI: $-0.10,0.09)$; prevalence of vacant lots, $\beta=-0.02$ (95\% CI: $-0.12,0.08$ ); and prevalence of community gardens, $\beta=0.00$ (95\% CI: $-0.10,0.10)$. In addition, we combined all of these measures into an aggregate neighborhood disorder score by summing them with community garden prevalence reverse coded. The aggregate score was associated with reduced thymic function, but was not statistically significant, $\beta=-0.02$ (95\% CI: $-0.11,0.08)$ (table 3, table A1).

\section{Mediation Analyses}

The median neighborhood social cohesion score was 52 (IQR: 40 to 60). A 10 percent higher neighborhood prevalence of abandoned homes was significantly associated with lower social cohesion scores, $\beta=-0.27$ (95\% CI: $-0.43,-0.11$ ) as was 2009 foreclosure proportion $\beta=-0.09$ (95\% CI: $-0.14,-0.04)$. The neighborhood social cohesion score was positively associated with thymic output. A one-unit increase in the social cohesion variable was associated with a 0.05 (95\% CI: 0.02, 0.07) log-unit increase in sj/beta- 
Table 3. Regression Coefficient Estimates and 95 Percent Confidence Intervals, for the Associations of Neighborhood Prevalences

\begin{tabular}{|c|c|c|}
\hline Neighborhood Characteristic & $\beta(95 \% \mathrm{Cl})$ Adjusted for Age Only & $\beta(95 \% \mathrm{Cl})$ Fully Adjusteda \\
\hline $\begin{array}{l}\text { For each } 10 \text { percentage point increase in } \\
\text { abandoned home prevalence }\end{array}$ & -0.02 (95\% Cl: $-0.05,0.00)$ & $-0.03(95 \% \mathrm{Cl}:-0.05,-0.01)^{*}$ \\
\hline $\begin{array}{l}\text { For each } 10 \text { percentage point increase in } \\
\text { damaged property prevalence }\end{array}$ & -0.03 (95\% Cl: $-0.08,0.06)$ & $-0.04 \quad(95 \% \mathrm{Cl}:-0.10,0.09)$ \\
\hline $\begin{array}{l}\text { For each } 10 \text { percentage point increase in } \\
\text { vacant lot prevalence }\end{array}$ & -0.02 (95\% Cl: $-0.09,0.07)$ & -0.02 (95\% Cl: $-0.12,0.08)$ \\
\hline $\begin{array}{l}\text { For each } 1 \text { percentage point increase in } \\
\text { community garden prevalence }\end{array}$ & $0.01 \quad(95 \% \mathrm{Cl}:-0.11,0.07)$ & $0.00 \quad(95 \% \mathrm{Cl}:-0.10,0.10)$ \\
\hline $\begin{array}{l}\text { For each } 10 \text { percentage point increase in } \\
\text { composite environment score }\end{array}$ & -0.02 (95\% Cl: $-0.11,0.08)$ & -0.02 (95\% Cl: $-0.11,0.08)$ \\
\hline $\begin{array}{l}\text { For each } 1 \text { percentage point increase in } 2009 \\
\text { foreclosures }\end{array}$ & $-0.07(95 \% \mathrm{Cl}:-0.11,-0.02)^{*}$ & $-0.06(95 \% \mathrm{Cl}:-0.11,-0.01)^{*}$ \\
\hline $\begin{array}{l}\text { For each } 1 \text { percentage point increase in } 2011 \\
\text { foreclosures }\end{array}$ & $-0.03(95 \% \mathrm{Cl}:-0.07,0.01)$ & -0.04 (95\% Cl: $-0.09,0.00)$ \\
\hline $\begin{array}{l}\text { For each } 1 \text { percentage point increase in } \\
\text { foreclosure change }(2009-2011)\end{array}$ & $-0.11(95 \% \mathrm{Cl}:-0.54,0.17)$ & -0.19 (95\% Cl: $-0.62,0.24)$ \\
\hline
\end{tabular}

Source: Authors' calculations from the Detroit Neighborhood Health Study, 2008, and Detroit Police Department 2009.

${ }^{a}$ Adjusted for age, sex, baseline IL-6, and employment status. Coefficient estimates represent the change in log $\mathrm{sj} /$ beta-TREC ratio associated with a 10 percentage point increase in prevalence of environmental characteristics and a one per 100 mortgage increase in foreclosure rates.

*significant at the $\alpha=.05$ level.

TREC ratio. Abandoned homes and foreclosure proportions were similarly distributed spatially, and some spatial consistency in distributions of neighborhood social cohesion was evident (figure 3). Inclusion of social cohesion in the main models estimating the association of neighborhood prevalence of abandoned homes and 2009 foreclosure proportions with thymic function resulted in attenuation of the effect estimates, $\beta=0.00$ (95\% CI: $-0.36,0.18)$ (figure 4) and $\beta=-0.03(-0.06,0.00)$ (figure 5), respectively.

The median number of population-size adjusted violent crimes per square mile was 436 (IQR: 374 to 516). A 10 percentage point increase in neighborhood prevalence of abandoned homes was associated with a 0.06 ( $95 \%$ CI: 0.02, $0.10)$ unit increase in violent crimes per square mile, and a 1 percentage point increase in 2009 foreclosures was associated with a $0.08(95 \%$ CI: $0.00,0.14$ ) unit increase. Our model findings did not support the theory that crime was associated with a decline in thymic function, $\beta=0.00$ (95\% CI: $-0.03,0.01)$ and therefore did not meet justification for exploring mediation by crime in further analyses.

\section{Stratified Analyses}

In analyses stratified by household income level, associations between abandoned home prevalence and foreclosure proportions in 2009 and 2011 were strongest in the middle-income group, $\beta=-0.10$ (95\% CI: $-0.26,0.06) ;=\beta=-0.11$ (95\% CI: $-0.29,0.07)$; and $\beta=-0.08$ (95\% CI: $-0.18,0.02)$, respectively. Among the lowest income group, associations were weak but the association between change in foreclosure proportions and thymic function was strongest, $\beta$ $\beta=-0.21$ (95\% CI: $-0.50,0.08)$. Associations were weakest among the highest income group and no estimates were statistically significant at the $\alpha=0.05$ level (table 4 ). In the full model, including an interaction term did not improve fit, nor was the term (testing heterogeneity of effect across levels of individual-level income) statistically significant. 
Figure 3. Spatial Distributions by Neighborhood $(N=52)$
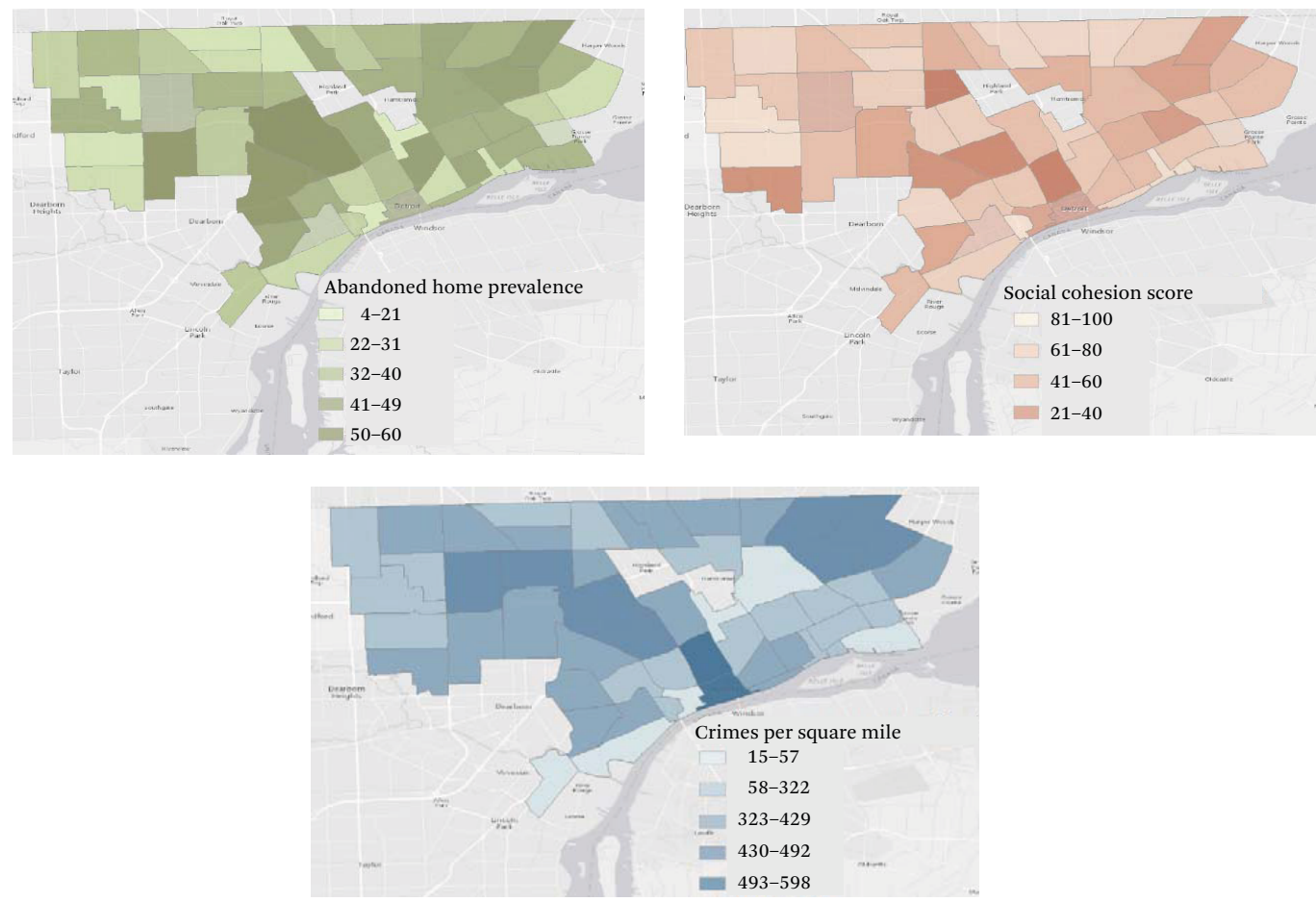

Source: Authors' calculations from the Detroit Neighborhood Health Study, 2008, and Detroit Police Department 2009.

Figure 4. Regression Coefficients and 95 Percent Confidence Intervals, Mediation Analysis, Abandoned Homes

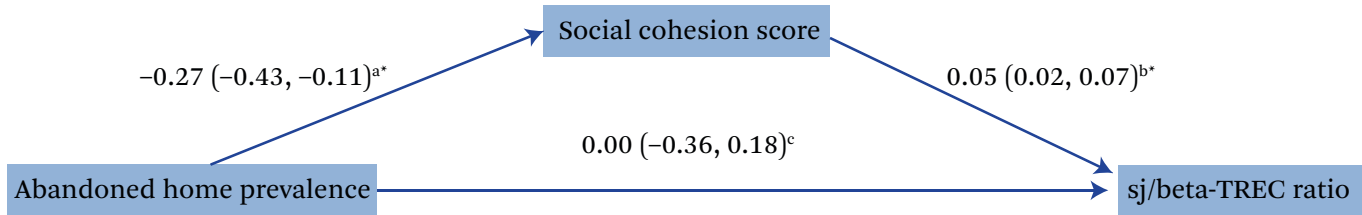

Source: Authors' calculations from the Detroit Neighborhood Health Study, 2008, and Detroit Police Department 2009.

aModel adjusted for age, sex, baseline IL-6, and employment status.

${ }^{b}$ Model adjusted for age, sex, baseline IL-6, employment status, abandoned home prevalence, and 2009 foreclosure prevalence.

'Model adjusted for social cohesion, age, sex, and employment status.

*significant at the $\alpha=.05$ level. 
Figure 5. Regression Coefficients and 95 Percent Confidence Intervals, Mediation Analysis, Foreclosure Rate

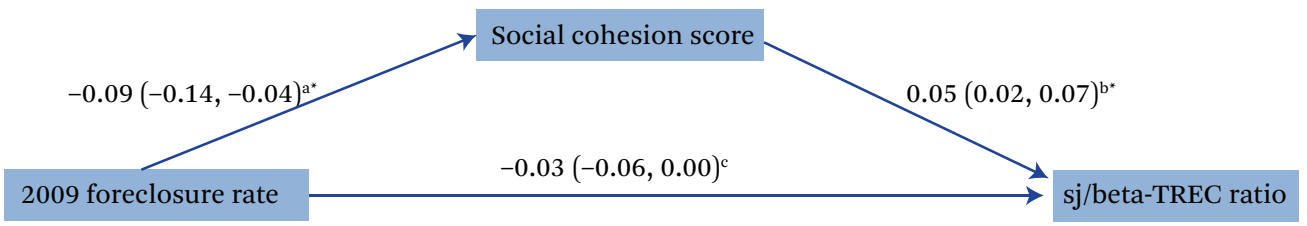

Source: Authors' calculations from the Detroit Neighborhood Health Study, 2008, and Detroit Police Department 2009.

aModel adjusted for age, sex, baseline IL-6, and employment status.

${ }^{b}$ Model adjusted for age, sex, baseline IL-6, employment status, abandoned home prevalence, and 2009 foreclosure prevalence.

'Model adjusted for social cohesion, age, sex, and employment status.

*significant at the $\alpha=.05$ level.

Table 4. Regression Coefficient Estimates and 95 Percent Confidence Intervals, Associations of Neighborhood Prevalence, by Income Group

\begin{tabular}{|c|c|c|}
\hline Neighborhood Characteristic & $\beta(95$ & $\%$ Cl) Fully Adjusteda \\
\hline \multicolumn{3}{|l|}{ High income $(\geq \$ 50,000$ per year) } \\
\hline $\begin{array}{l}\text { For each } 10 \text { percentage point increase in abandoned home } \\
\text { prevalence }\end{array}$ & 0.01 & (95\% Cl: $-0.05,0.07)$ \\
\hline For each 1 percentage point increase in 2009 foreclosures & 0.00 & (95\% Cl: $-0.10,0.10)$ \\
\hline For each 1 percentage point increase in 2011 foreclosures & -0.02 & (95\% Cl: $-0.10,0.06)$ \\
\hline $\begin{array}{l}\text { For each } 1 \text { percentage point increase in foreclosure change } \\
(2009-2011)\end{array}$ & -0.07 & (95\% Cl: $-0.15,0.01)$ \\
\hline \multicolumn{3}{|l|}{ Middle income $(\$ 25,000$ to $<\$ 50,000$ per year) } \\
\hline $\begin{array}{l}\text { For each } 10 \text { percentage point increase in abandoned home } \\
\text { prevalence }\end{array}$ & -0.10 & (95\% Cl: $-0.26,0.06)$ \\
\hline For each 1 percentage point increase in 2009 foreclosures & -0.11 & (95\% Cl: $-0.29,0.07)$ \\
\hline For each 1 percentage point increase in 2011 foreclosures & -0.08 & (95\% Cl: $-0.18,0.02)$ \\
\hline $\begin{array}{l}\text { For each } 1 \text { percentage point increase in foreclosure change } \\
(2009-2011)\end{array}$ & -0.13 & (95\% Cl: $-0.29,0.03)$ \\
\hline \multicolumn{3}{|l|}{ Low income $(\leq \$ 25,000$ per year) } \\
\hline $\begin{array}{l}\text { For each } 10 \text { percentage point increase in abandoned home } \\
\text { prevalence }\end{array}$ & -0.02 & $(95 \% \mathrm{Cl}:-0.08,0.04)$ \\
\hline For each 1 percentage point increase in 2009 foreclosures & -0.01 & (95\% Cl: $-0.03,0.01)$ \\
\hline For each 1 percentage point increase in 2011 foreclosures & 0.00 & (95\% Cl: $-0.12,0.12)$ \\
\hline $\begin{array}{l}\text { For each } 1 \text { percentage point increase in foreclosure change } \\
(2009-2011)\end{array}$ & -0.21 & (95\% Cl: $-0.50,0.08)$ \\
\hline
\end{tabular}

Source: Authors' calculations from the Detroit Neighborhood Health Study, 2008, and Detroit Police Department 2009.

${ }^{a}$ Adjusted for age, sex, baseline IL-6, and employment status. Coefficient estimates represent the change in log sj/beta-TREC ratio associated with a 10 percentage point increase in prevalence of environmental characteristics and a 1 percentage point increase in foreclosure prevalence. 


\section{Sensitivity Analyses}

We examined whether differing individual-level socioeconomic variables affected the association between abandoned homes and thymic function. The estimated association between abandoned homes and sj/beta-TREC ratio differed little when controlling for income instead of employment status in fully adjusted models for $\log \mathrm{sj} /$ beta-TREC ratio, $\beta=-0.05$ (95\% CI: $-0.15,0.05)$. We had similar findings when controlling for education rather than employment status, $\beta=-0.03$ ( $95 \%$ CI: $-0.13,0.07$ ), suggesting that the influence of individual measures of socioeconomic status are similar and do not fully account for the influence of abandoned homes at the neighborhood level.

When assessing sensitivity to the thymic function measurement approach, neighborhood prevalence of abandoned homes was also associated with decline in thymic function as measured by the number of sjTREC per million whole blood cells, $\beta=-0.02$ (95\% CI: -0.12 , 0.08 ), but this estimate was not statistically significant at the $\alpha=0.05$ level. Similarly, abandoned home prevalence was associated with higher baseline inflammation (as measured by IL-6 level), $\beta=0.12$ (95\% CI: $-0.02,0.17$ ), as were neighborhood foreclosures $\beta=0.08$ (95\% CI: $-0.05,0.21)$.

\section{DISCUSSION}

In this community-based study of adults living in Detroit in 2009, the height of the Great Recession impact on home prices and household wealth (U.S. Census Bureau 2013), we assessed the association between area-level indicators of the economic crisis-including neighborhood prevalence of abandoned homes, home foreclosure, and other measures of neighborhood disorder-and thymic function, a key measure of immunological well-being. We found that increased neighborhood prevalence of abandoned homes and home foreclosure during the recession were associated with decreased thymic function, particularly among middle-income individuals. Indeed, even after adjusting for covariates, a 10 percentage point increase in neighborhood prevalence of abandoned homes was roughly associated with the same decrease in thymic function as we observed for a 1.7-year increase in chronological age, and a 1 percentage point increase in 2009 home foreclosures was associated with the same decrease in thymic function as we observed for a 3.3-year increase in chronological age. Additionally, our findings support the hypothesis that social cohesion mediates the association between neighborhood environment and immune function. These findings strengthen the body of evidence supporting the significance of social context in influencing key biological health indicators over the life course, and, more specifically, stress-sensitive markers of immunity.

Given the economic climate and high home foreclosure rate in Detroit during the Great Recession, neighborhood prevalence of abandoned and foreclosed homes is an important source of chronic stress in the study population (Rooney 2008). We observed associations with reduced thymic function when assessing both prevalence of abandoned homes and foreclosure proportions. We also examined other measures of the physical environment (such as damaged property, gardens, and vacant lots) and found associations that, though not statistically significant, were consistent with our main findings that neighborhood quality affects health through immunological pathways. The robust and specific influence of abandoned homes and home foreclosures on our immune function measure underscore the importance of addressing structural factors influencing poor health outcomes and contributing to social health disparities in this population.

We are not aware of any other studies assessing the relationship between measures related to the Great Recession or neighborhood environment and thymic function. However, our findings complement the scant literature examining the association between neighborhood characteristics and general biological markers of health. Specifically, neighborhood affluence was found to be protective with respect to a measure of cumulative biological health (King, Morenoff, and House 2011) and type 2 diabetes (Piccolo et al. 2015). Several studies have also shown associations between foreclosure rates, mental health, and cardiovascular disease risk, suggesting that foreclosure stressors may ultimately influence health (Burgard, Ailshire, and Kalousova 2013; Cata- 
lano et al. 2011). Our work provides additional evidence in support for a potential biological mediator of these reported associations by examining a global measure of immune function, which is critical for fighting disease and promoting health.

The potential influence of stressors related to the Great Recession on thymic function is significant because it supports existing evidence that exposure to stressors negatively impacts the immune system (Dhabhar 2014). It may also influence overall health in adulthood, because the role of the thymus is important for production of naïve T-cells throughout the life course (Poulin et al. 1999). For example, decline in thymic function has been found to be associated with increased infection susceptibility as well as risk of autoimmune disease, cancer, and mortality (Ferrando-Martínez et al. 2013; Lynch et al. 2009). Further, our earlier research in the DNHS cohort suggests that reduced thymic function is associated with increased levels of pro-inflammatory biomarkers and other negative health outcomes, highlighting this measure as an important potential mechanism by which stressors may influence health at the population level (Feinstein et al. 2016).

Although we observed a significant association between foreclosures in 2009 and thymic function, our analyses did not identify a significant impact of changes in foreclosure prevalence from 2009 to 2011. Foreclosures were declining on average in that period. Indeed, 2009 showed the largest dip in home sale prices and loss of household wealth; in 2011, these measures began to bounce back (U.S. Census Bureau 2013). Therefore, 2011 represents a period of recovery, which may explain our findings. We also may not have captured the period of the most severe recession impacts for all neighborhoods. Moreover, Detroit experienced a history of industrial collapse, discriminatory residential lending, and racial segregation that had left many parts of the city vulnerable and under resourced decades before the Great Recession, which may have augmented the recession impacts in 2009 (Sugrue 2014).

Results of stratified analyses supported the hypothesis that socioeconomic status modifies the effect of abandoned homes and foreclosures on thymic function. Although the effects by income were not significantly different, the subgroup sample sizes did not provide adequate statistical power to detect heterogeneity. However, the differences in estimated effects by income group are of substantive interest. Individuals in the middle-income group showed the strongest association between increased abandoned home prevalence and prevalence of foreclosures and poorer immune function. This supports the theory that middleincome individuals were most sensitive to the impacts of area-level foreclosures and home vacancies. We observed that, among those in the lowest income group, changes in home foreclosure proportions from 2009 to 2011 (as opposed to prevalence of foreclosures in 2009, as observed for higher income groups) had the strongest impact on thymic function, suggesting that these individuals may have been particularly susceptible to ongoing changes in housing stability following the Great Recession. Previous work has found stronger impacts on physiological manifestations of major, recession-related financial stressors among low-income individuals (Boen and Yang 2016).

Our mediation analyses support the hypothesis that social cohesion may lie on the pathway between living in an adverse neighborhood environments and individual-level immune function. A higher prevalence of abandoned homes and foreclosure in the neighborhood were associated with lower social cohesion; higher social cohesion was associated with decreased thymic function. Further, adjustment for social cohesion attenuated the estimated effect of foreclosure and abandoned home prevalence on thymic function toward the null estimate. Our results support the growing literature suggesting that the level of social cohesion within neighborhoods is an important protective, mediating factor for mental health outcomes among African American women (Giurgescu et al. 2015) and the general U.S. population (Drukker and van Os 2003; Kruger, Reischl, and Gee 2007) as well as cardiovascular health in the United States (Diez Roux et al. 2001).

The number of population-adjusted crimes per square mile was associated with the prevalence of abandoned homes and foreclosure proportion, but was not associated with decreased thymic output. Given the administrative source 
of the crime data, we are aware that error is likely to be present in this measure (Black 1970; Biderman and Lynch 2012). Further work using more extensive crime data, such as crowdsourced crime information, may help support a more robust analysis of this potential mediator (Shah et al. 2011). In addition to mechanistic insights, the roles of crime and social cohesion in the association between neighborhood environment and immune function also highlight the potential for community-level intervention opportunities for mitigating the deleterious effects of poor neighborhood physical environments.

Important strengths of this study include data from a predominantly African American, population-based sample and representation from neighborhoods with a wide variance in quality of the physical and social environments. The analyses were also strengthened by the use of a novel measure of immune health, which has been specifically characterized in the DNHS population (Feinstein et al. 2016). However, this study has some limitations. First, although the sj/beta-TREC ratio measure addresses peripheral blood dilution of sjTRECs (Dion et al. 2004), not all beta excision circles are captured, complicating interpretations of low function values (Ferrando-Martínez et al. 2010). Second, as in all nonexperimental studies of neighborhood characteristics and health, our study may suffer from issues related to selection into neighborhoods that may be related to the outcome (Oakes 2004). Therefore, the estimated effects may be an artifact of unmeasured factors both enabling some Detroit residents to move to neighborhoods with less foreclosure and causing them to have better immune function. However, the robustness of analyses to confounder adjustment, including a marker of immune health at baseline, provide enough confidence in the association to warrant further pursuit in a longitudinal or quasiexperimental setting in which a causal effect may be estimated. Third, our measure of abandoned homes was derived in 2008 , only about a year into the Great Recession. We do not have data on duration of abandonment, and therefore some of the abandoned homes that were quantified may have been abandoned before the recession. Fourth, police department data are vulnerable to misclassification (approximated to fit available codes). Crime incident data are also biased by the absence of crimes not reported by citizens to the police and by police decisions not to record all crimes reported by citizens (Black 1970). Fifth, this analysis may be limited by the conceptualization of neighborhood. Historic administrative units defining neighborhoods in this study may not reflect the true function of the included arealevel variables. Regardless, neighborhood definitions based on historically defined boundaries are likely a substantial improvement over measurements based on census tracts (Duncan et al. 2014). Sixth, the differences in the distribution of some sociodemographic characteristics of our study sample relative to the full DNHS study population may limit the generalizability of our results to the entire city of Detroit. We mitigated threats to internal validity by controlling for identified confounders distributed differently between the study sample and overall population. Finally, the analyses were limited by the small sample size of participants with available thymic function data, which may have under powered analyses to detect statistically significant effects in some instances, particularly those assessing heterogeneity of effect by individual income. However, the robust and consistent associations we did observe over multiple measures and despite our relatively small sample size suggest important immune health impacts of the Great Recession in part due to the profound proliferation of home foreclosures and subsequent neighborhood vacancy, which warrant further investigation.

This study, for the first time, suggests a population-level association between abandoned homes, home foreclosures, and a key global marker of immune function among Detroit residents. Although immune function is an objective and upstream measure that directly influences many health outcomes, it has not previously been assessed in relation to measures of the neighborhood environment. If the association that we observed here is causal, it may have far-reaching implications for addressing the health and well-being of individuals living in neighborhoods characterized by foreclosures and abandoned homes. Moreover, our 
results suggest that social cohesion may be an important buffering community-level factor that could reduce the detrimental impacts of living in neighborhoods during economic declines. The finding that social cohesion may mediate the association of abandoned homes and foreclosures with thymic function supports the hypothesis that neighborhoods may influ- ence health through psychosocial mechanistic pathways. Future research is needed to identify the mechanisms through which neighborhoodlevel economic stressors impact health, particularly the role of historically determined arealevel vulnerability in the context of a recession on biological pathways that influence health and well-being. 


\section{APPENDIX}

Table A1. Regression Coefficient Estimates and Confidence Intervals, Associations of Neighborhood

Prevalence, by Age

\begin{tabular}{|c|c|c|}
\hline \multirow{2}{*}{$\begin{array}{l}\text { Neighborhood Characteristic } \\
\text { For each } 10 \text { percentage point increase in abandoned home } \\
\text { prevalence }\end{array}$} & \multicolumn{2}{|c|}{$\beta(95 \% \mathrm{Cl})$ Fully Adjusteda } \\
\hline & -0.03 & $(95 \% \mathrm{Cl}:-0.05,-0.01)^{\mathrm{b}}$ \\
\hline Age node $1^{\mathrm{b}}$ & -0.15 & $(95 \% \mathrm{Cl}:-0.25,-0.07)^{\mathrm{b}}$ \\
\hline Age node $2^{\mathrm{b}}$ & -0.01 & (95\% Cl: $-0.04,0.00)$ \\
\hline Age node $3^{\mathrm{b}}$ & 0.04 & (95\% Cl: $-0.05,0.11)$ \\
\hline Age node $4^{b}$ & 0.01 & (95\% Cl: $-0.03,0.04)$ \\
\hline Female & -0.33 & (95\% Cl: $-0.68,0.02)$ \\
\hline Baseline IL-6 & 0.02 & (95\% Cl: $-0.02,0.05)$ \\
\hline Unemployed & -0.31 & (95\% Cl: $-0.85,0.23)$ \\
\hline Other employment & 0.21 & (95\% Cl: $-0.20,0.62)$ \\
\hline For each 1 percentage point increase in 2009 foreclosures & -0.06 & $(95 \% \mathrm{Cl}:-0.11,-0.01)^{*}$ \\
\hline Age node $1^{\mathrm{b}}$ & -0.12 & $(95 \% \mathrm{Cl}:-0.22,-0.04)^{\mathrm{b}}$ \\
\hline Age node $2^{\mathrm{b}}$ & 0.00 & (95\% Cl: $-0.04,0.02)$ \\
\hline Age node $3^{b}$ & 0.04 & (95\% Cl: $-0.03,0.12)$ \\
\hline Age node $4^{b}$ & 0.02 & (95\% Cl: $-0.01,0.06)$ \\
\hline Female & -0.31 & (95\% Cl: $-0.61,0.00)$ \\
\hline Baseline IL-6 & 0.03 & (95\% Cl: $-0.02,0.06)$ \\
\hline Unemployed & -0.28 & (95\% Cl: $-0.81,0.19)$ \\
\hline Other employment & 0.18 & (95\% Cl: $-0.17,0.53)$ \\
\hline For each 1 percentage point increase in 2011 foreclosures & -0.04 & $(95 \% \mathrm{Cl}:-0.09,0.00)$ \\
\hline Age node $1^{\mathrm{b}}$ & -0.14 & $(95 \% \mathrm{Cl}:-0.27,-0.06)^{\mathrm{b}}$ \\
\hline Age node $2^{\mathrm{b}}$ & -0.03 & $(95 \% \mathrm{Cl}:-0.08,0.00)$ \\
\hline Age node $3^{\mathrm{b}}$ & 0.01 & (95\% Cl: $-0.06,0.04)$ \\
\hline Age node $4^{\mathrm{b}}$ & 0.04 & $(95 \% \mathrm{Cl}:-0.03,0.02)$ \\
\hline Female & -0.33 & (95\% Cl: $-0.61,0.07)$ \\
\hline Baseline IL-6 & 0.05 & (95\% Cl: 0.00, 0.11) \\
\hline Unemployed & -0.30 & $(95 \% \mathrm{Cl}:-0.83,0.21)$ \\
\hline Other employment & 0.18 & (95\% Cl: $-0.21,0.45)$ \\
\hline For each 1 percentage point increase in foreclosure & -0.19 & (95\% Cl: $-0.62,0.24)$ \\
\hline \multicolumn{3}{|l|}{ change (2009-2011) } \\
\hline Age node $1^{\mathrm{b}}$ & -0.17 & $(95 \% \mathrm{Cl}:-0.28,-0.07)^{\mathrm{b}}$ \\
\hline Age node $2^{\mathrm{b}}$ & -0.06 & (95\% Cl: $-0.12,0.01)$ \\
\hline Age node $3^{b}$ & 0.01 & (95\% Cl: $-0.07,0.09)$ \\
\hline Age node $4^{b}$ & 0.05 & $(95 \% \text { Cl: } 0.01,0.17)^{b}$ \\
\hline Female & -0.35 & (95\% Cl: $-0.72,0.18)$ \\
\hline Baseline IL-6 & 0.05 & (95\% Cl: 0.00, 0.11) \\
\hline Unemployed & -0.30 & $(95 \% \mathrm{Cl}:-0.83,0.18)$ \\
\hline Other employment & 0.12 & (95\% Cl: $-0.21,0.43)$ \\
\hline
\end{tabular}

Source: Authors' calculations from the Detroit Neighborhood Health Study, 2008, and Detroit Police Department 2009.

${ }^{a}$ Adjusted for age, sex, baseline IL-6, and employment status. Coefficient estimates represent the change in log sj/beta-TREC ratio associated with a 10 percentage point increase in prevalence of environmental characteristics and a 1 percentage point increase in foreclosure prevalence.

${ }^{\mathrm{b}}$ Age was modeled as a 4-node cubic spline.

*Significant at the $=.05$ level. 


\section{REFERENCES}

Ackerman, Robert Argento, Gerhard Fries, and Richard A. Windle. 2012. “Changes in U.S. Family Finances from 2007 to 2010: Evidence from the Survey of Consumer Finances." Federal Reserve Bulletin 100(4): 1-80.

Auchincloss, Amy H., Ana V. Diez Roux, Daniel G. Brown, Trivellore E. Raghunathan, and Christine A. Erdmann. 2007. "Filling the Gaps: Spatial Interpolation of Residential Survey Data in the Estimation of Neighborhood Characteristics." Epidemiology 18(4): 469-78.

Bacigalupe, Amaia, and Antonio Escolar-Pujolar. 2014. "The Impact of Economic Crises on Social Inequalities in Health: What Do We Know So Far?" International Journal for Equity in Health 13: 52. DOI: 10.1186/1475-9276-13-52.

Biderman, Albert D., and James P. Lynch. 2012. Understanding Crime Incidence Statistics: Why the UCR Diverges from the NCS. New York: Springer. Black, Donald J. 1970. "Production of Crime Rates." American Sociological Review 35(4): 733-48.

Blair, Alexandra, Nancy A. Ross, Geneviève Gariepy, and Norbert Schmitz. 2014. "How Do Neighborhoods Affect Depression Outcomes? A Realist Review and a Call for the Examination of Causal Pathways." Social Psychiatry and Psychiatric Epidemiology 49(6): 873-87.

Boen, Courtney, and Y. Claire Yang. 2016. “The Physiological Impacts of Wealth Shocks in Late Life: Evidence from the Great Recession." Social Science \& Medicine 150 (February): 221-30. DOI: 10 .1016/j.socscimed.2015.12.029.

Bureau of Labor Statistics. 2015. “Local Area Unemployment Statistics Map: Michigan; Unemployment Rates by State; Not Seasonally Adjusted, Annual." Washington: U.S. Department of Labor. Accessed August 12, 2017. https://www.bls.gov /lau/.

Burgard, Sarah A, Jennifer A. Ailshire, and Lucie Kalousova. 2013. "The Great Recession and Health: People, Populations, and Disparities." Annals of the American Academy of Political and Social Science 650(1): 194-213.

Burgard, Sarah A., K. S. Seefeldt, and S. Zelner. 2012. "Housing Instability and Health: Findings from the Michigan Recession and Recovery Study." Social Science \& Medicine 75(12): 221524.

Cagney, K. A., C. R. Browning, J. Iveniuk, and N. English. 2014. "The Onset of Depression During the
Great Recession: Foreclosure and Older Adult Mental Health." American Journal of Public Health 104(3): 498-505.

Catalano, Ralph, Sidra Goldman-Mellor, Katherine Saxton, Claire Margerison-Zilko, Meenakshi Subbaraman, Kaja LeWinn, and Elizabeth Anderson. 2011. "The Health Effects of Economic Decline." Annual Review of Public Health 32: 431-50. DOI: 10.1146/annurev-publhealth-031210-101146.

Curry, Aaron, Carl Latkin, and Melissa DaveyRothwell. 2008. “Pathways to Depression: The Impact of Neighborhood Violent Crime on InnerCity Residents in Baltimore, Maryland, USA." Social Science \& Medicine 67(1): 23-30.

DelaRosa, Olga, Graham Pawelec, Esther Peralbo, Anders Wikby, Erminia Mariani, Eugenio Mocchegiani, Raquel Tarazona, and Rafael Solana. 2006. "Immunological Biomarkers of Ageing in Man: Changes in Both Innate and Adaptive Immunity Are Associated with Health and Longevity." Biogerontology 7(5-6): 471-81.

Detroit Police Department. 2009. "CrisNet/NetRMS." Detroit Open Data. Accessed August 12, 2017. https://data.detroitmi.gov/.

Dhabhar, Firdaus S. 2014. "Effects of Stress on Immune Function: The Good, the Bad, and the Beautiful." Immunological Research 58(2-3): 193210.

Diez Roux, Ana V., Sharon S. Merkin, Donna Arnett, Lloyd Chambless, Mark Massing, F. Javier Nieto, Paul Sorlie, Moyses Szklo, Herman A. Tyroler, and Robert L. Watson. 2001. “Neighborhood of Residence and Incidence of Coronary Heart Disease." New England Journal of Medicine 345(2): 99-106.

Dion, M. L., R. Bordi, J. Zeidan, R. Asaad, M. R. Boulassel, J. P. Routy, M. M. Lederman, R. P. Sékaly, and R. Cheynier. 2007. "Slow Disease Progression and Robust Therapy-Mediated CD4+ T-cell Recovery Are Associated with Efficient Thymopoiesis During HIV-1 Infection." Blood 109(7): 2912-20.

Dion, Marie-Lise, Jean-Françoise Poulin, Rebeka Bordi, Myriam Sylvestre, Rachel Corsini, Nadia Kettaf, Ali Dalloul, Mohamed-Rachid Boulassel, Patrice Debré, Jean-Pierre Routy, Zvi Grossman, Rafick-Pierre Sékaly, and Rémi Cheynier. 2004. "HIV Infection Rapidly Induces and Maintains a Substantial Suppression of Thymocyte Proliferation." Immunity 21(6): 757-68.

Douek, Daniel C., Richard D. McFarland, Philip H. 
Keiser, Earl A. Gage, et al. 1998. “Changes in Thymic Function with Age and During the Treatment of HIV Infection." Nature 396(6712): 69095.

Dowd, Jennifer B., and Allison E. Aiello. 2009. "Socioeconomic Differentials in Immune response." Epidemiology 20(6): 902-08.

Drukker, Marjan, and Jim van Os. 2003. “Mediators of Neighbourhood Socioeconomic Deprivation and Quality of Life." Social Psychiatry and Psychiatric Epidemiology 38(12): 698-706.

Duncan, Dustin T., Ichiro Kawachi, S. V. Subramanian, Jared Aldstadt, Steven J. Melly, and David R. Williams. 2014. “Examination of How Neighborhood Definition Influences Measurements of Youths' Access to Tobacco Retailers: A Methodological Note on Spatial Misclassification." American Journal of Epidemiology 179(3): 373-81.

Feinstein, Lydia, Sara Ferrando-Martínez, Manuel Leal, Xuan Zhou, Gregory D. Sempowski, Derek E. Wildman, Monica Uddin, and Allison E. Aiello. 2016. "Population Distributions of Thymic Function in Adults: Variation by Sociodemographic Characteristics and Health Status." Biodemography and Social Biology 62(2): 208-21.

Ferrando-Martínez, Sara, Jaime M. Franco, Ana Hernandez, Antonio Ordoñez, Encarna Gutierrez, Antonia Abad, and Manuel Leal. 2009. “Thymopoiesis in Elderly Human Is Associated with Systemic Inflammatory Status." Age (Dordr) 31(2): 87-97.

Ferrando-Martínez, Sara, Jaime M. Franco, Ezequiel Ruiz-Mateos, Anna Hernandez, Antonio Ordonez, Encarnacion Gutiérrez-Carretero, and Manuel Leal. 2010. "A Reliable and Simplified sj/betaTREC Ratio Quantification Method for Human Thymic Output Measurement." Journal of Immunological Methods 352(1-2): 111-17.

Ferrando-Martínez, Sara, Maria C. Romero-Sanchez, Rafael Solana, Juan Delgado, Rafael de la Rosa, Ma Angeles Munoz-Fernandez, Ezequiel RuizMateos, and Manuel Leal. 2013. “Thymic Function Failure and C-Reactive Protein Levels Are Independent Predictors of All-Cause Mortality in Healthy Elderly Humans." Age (Dordr) 35(1): 25159.

Flanagan, Christine, and Ellen Wilson. 2013. "Home Value and Homeownership Rates: Recession and Post-Recession Comparisons from 2007-2009 to 2010-2012." American Community Survey Brief 12-20. Washington: U.S. Census Bureau.
Ford, Jodi L., and Christopher R. Browning. 2015. “Exposure to Neighborhood Immigrant Concentration from Adolescence to Young Adulthood and Immune Function Among Latino Young Adults." Health \& Place 32(1): 59-64.

Giurgescu, Carmen, Dawn P. Misra, Shawnita SealyJefferson, Cleopatra H. Caldwell, Thomas N. Templin, Jaime C. Slaughter-Acey, and Theresa L. Osypuk. 2015. “The Impact of Neighborhood Quality, Perceived Stress, and Social Support on Depressive Symptoms During Pregnancy in African American Women." Social Science \& Medicine 130 (April): 172-80.

Goldmann, Emily, Allison Aiello, Monica Uddin, Jorge Delva, Karestan Koenen, Larry M. Gant, and Sandro Galea. 2011. “Pervasive Exposure to Violence and Posttraumatic Stress Disorder in a Predominantly African American Urban Community: The Detroit Neighborhood Health Study." Journal of Traumatic Stress 24(6): 747-51.

Gould Ellen, Ingrid, and Samuel Dastrup. 2012. "Housing and the Great Recession." Stanford Center on Poverty and Inequality, October. Accessed August 12, 2017. http://furmancenter.org /files/publications/HousingandtheGreat Recession.pdf.

Greenland, Sander, Judea Pearl, and James M. Robins. 1999. “Causal Diagrams for Epidemiologic Research." Epidemiology 10(1): 37-48.

Gruver, Amanda L., and Gregory D. Sempowski. 2008. “Cytokines, Leptin, and Stress-Induced Thymic Atrophy." Journal of Leukocyte Biology 84(4): 915-23.

Hill, Eric J., and John Gallagher. 2002. AIA Detroit: The American Institute of Architects Guide to Detroit Architecture. Detroit, Mich.: Wayne State University Press.

Howe, Chanelle J., Stephen R. Cole, Daniel J. Westreich, Sander Greenland, Sonia Napravnik, and Joseph J. Eron Jr. 2011. “Splines for Trend Analysis and Continuous Confounder Control." Epidemiology 22(6): 874-45.

Hunter, Christopher A., and Simon A. Jones. 2015. "IL-6 as a Keystone Cytokine in Health and Disease." Nature Immunology 16(5): 448-57.

Kawachi, Ichiro, and Lisa F. Berkman. 2003. Neighborhoods and Health. Oxford: Oxford University Press.

Keita, Akilah Dulin, Suzanne E. Judd, Virginia J. Howard, April P. Carson, Jamy D. Ard, and Jose R. Fernandez. 2014. “Associations of Neighborhood 
Area Level Deprivation with the Metabolic Syndrome and Inflammation Among Middle- and Older-Age Adults." BMC Public Health 14 (December): 1319.

King, Katherine E., Jeffrey D. Morenoff, and James S. House. 2011. “Neighborhood Context and Social Disparities in Cumulative Biological Risk Factors." Psychosomatic Medicine 73(7): 572-79.

Kruger, Daniel J, Thomas M. Reischl, and Gilbert C. Gee. 2007. "Neighborhood Social Conditions Mediate the Association Between Physical Deterioration and Mental Health." American Journal of Community Psychology 40(3-4): 261-71.

Lantos, Paul M, Sallie R. Permar, Kate Hoffman, and Geeta K. Swamy. 2015. “The Excess Burden of Cytomegalovirus in African American Communities: A Geospatial Analysis." Open Forum Infectious Diseases 2(4). DOI: 10.1093/ofid/ofv180.

Lichter, Daniel T., Domenico Parisi, and Michael C. Taquino. 2015. "Toward a New MacroSegregation? Decomposing Segregation Within and Between Metropolitan Cities and Suburbs." American Sociological Review 80(4): 843-73.

Lynch, Heather E., Gabrielle L. Goldberg, Ann Chidgey, Marcel R. M. Van den Brink, Richard Boyd, and Gregory D. Sempowski. 2009. “Thymic Involution and Immune Reconstitution." Trends in Immunology 30(7): 366-73.

Lynch, Heather E., and G. D. Sempowski. 2013. “Molecular Measurement of T Cell Receptor Excision Circles." Methods in Molecular Biology 979: 14759.

McLaughlin, Katie A., A. Nandi, Kyle M. Keyes, Monica Uddin, Allison E. Aiello, Sandro Galea, and Karestan C. Koenen. 2012. “Home Foreclosure and Risk of Psychiatric Morbidity During the Recent Financial Crisis." Psychological Medicine 42(7): 1441-48.

Michigan Foreclosure Task Force. 2016. “Michigan Historical Residential Foreclosure Data." Johnson Center at Grand Valley State University, October 20, 2016. Accessed August 12, 2017. http://cridata.org/michiganforeclosuretaskforce/.

Mishel, Lawrence, Josh Bivens, Elise Gould, and Heidi Shierholz. 2012. "Great Recession." In The State of Working America, 12th ed. Ithaca, N.Y.: Cornell University Press.

Momper, Sandra, Anne Nordberg, Leah James, and Jorge Delva. 2012. “Assessing Neighborhoods' Physical and Social Environments: Experiences from the Detroit Neighborhood Health Study."
Paper presented at the Society for Social Work and Research Sixteenth Annual Conference "Research that Makes a Difference: Advancing Practice and Shaping Public Policy." Washington, D.C. (January 11-15, 2012).

Mulia, Nina, Sarah E. Zemore, Ryan Murphy, HiuGuo Liu, and Ralpj Catalano. 2014. “Economic Loss and Alcohol Consumption and Problems During the 2008 to 2009 U.S. Recession." Alcoholism: Clinical and Experimental Research 38(4): 102634.

Oakes, J. Michael. 2004. "The (Mis) Estimation of Neighborhood Effects: Causal Inference for a Practicable Social Epidemiology." Social Science \& Medicine 58(10): 1929-52.

Piccolo, Rebecca S., Dustin T. Duncan, Neil Pearce, and John B. McKinlay. 2015. "The Role of Neighborhood Characteristics in Racial/Ethnic Disparities in Type 2 Diabetes: Results from the Boston Area Community Health (BACH) Survey." Social Science \& Medicine 130 (April): 79-90.

Pollack, Craig E., Shanu K. Kurd, Alice Livshits, Mark G. Weiner, and Julia Lynch. 2011. "A Case-Control Study of Home Foreclosure, Health Conditions, and Health Care Utilization." Journal of Urban Health 88(3): 469-78.

Poulin, Jean-François, Mohan N. Viswanathan, Jeffrey M. Harris, Krishna V. Komanduri, Eric Wieder, Nancy Ringuette, Morgan Jenkins, Joseph M. McCune, and Rafick-Pierre Sékaly. 1999. “Direct Evidence for Thymic Function in Adult Humans." Journal of Experimental Medicine 190(4): 479-86.

RealtyTrac. 2011. "Michigan Foreclosures." RealtyTrac foreclosure activity. Accessed May 21, 2016. http://www.realtytrac.com/ContentManagement/. Riumallo-Herl, Carlos, Sanjay Basu, David Stuckler, Emilie Courtin, and Maricio Avendano. 2014. “Job Loss, Wealth and Depression During the Great Recession in the USA and Europe." International Journal of Epidemiology 43(5): 1508-17.

Rooney, Ben. 2008. "Rust and Sun Belt Cities Lean '07 Foreclosures: Detroit, Stockton and Las Vegas Are Top Activity Centers for Troubled Homeowners, According to New Study." CNN Money, February 12. Accessed August 12, 2017. http:// money.cnn.com/2008/02/12/real_estate/realty trac/index.htm.

Shah, Sumit, Fenye Bao, Chang-Tien Lu, and IngRay Chen. 2011. “Crowdsafe: Crowd Sourcing of Crime Incidents and Safe Routing on Mobile De- 
vices." Paper presented at the 19th ACM

SIGSPATIAL International Conference on Advances in Geographic Information Systems. Chicago (November 1-3, 2011).

Smith, George D., Carole Hart, Graham Watt, David Hole, and Victor Hawthorne. 1998. "Individual Social Class, Area-Based Deprivation, Cardiovascular Disease Risk Factors, and Mortality: The Renfrew and Paisley Study." Journal of Epidemiology and Community Health 52(6): 399405.

Steptoe, Andrew. 2012. Socioeconomic Status, Inflammation, and Immune Function. New York: Oxford University Press.

Steptoe, Andrew, and Michael Marmot. 2002. "The

Role of Psychobiological Pathways in Socio-

Economic Inequalities in Cardiovascular Disease Risk." European Heart Journal 23(1): 13-25.

Subramanian, S. V., and A. James O'Malley. 2010.

"Modeling Neighborhood Effects: The Futility of Comparing Mixed and Marginal Approaches." Epidemiology 21(4): 475-81.

Sugrue, Thomas J. 2014. The Origins of the Urban
Crisis: Race and Inequality in Postwar Detroit. Princeton, N.J.: Princeton University Press.

Tonorezos, Emily S., Patrick N. Breysse, Elizabeth C. Matsui, Meredith C. McCormack, Jean CurtinBrosnan, D'Ann Williams, Nadia N. Hansel, Peyton A. Eggleston, and Gregory B. Diette. 2008. “Does Neighborhood Violence Lead to Depression Among Caregivers of Children with Asthma?" Social Science \& Medicine 67(1): 31-37. Tsai, Alexander C. 2015. “Home Foreclosure, Health, and Mental Health: A Systematic Review of Individual, Aggregate, and Contextual Associations." PLoS One 10: e0123182.

U.S. Census Bureau. 2013. “Median and Average Sales Prices of New Homes Sold, Household Income in the United States." Accessed August 12, 2017. https://www.census.gov/construction/nrs /pdf/uspricemon.pdf.

Wilson-Genderson, Maureen, and Rachel Pruchno. 2013. "Effects of Neighborhood Violence and Perceptions of Neighborhood Safety on Depressive Symptoms of Older Adults." Social Science \& Medicine 85 (May): 43-49. 